\title{
Why is True eGovernment still difficult to be achieved?
}

\author{
Fugini Mariagrazia ${ }^{1}$, Maggiolini Piercarlo ${ }^{2}$, Nanini Krysnaia ${ }^{2}$ \\ ${ }^{1}$ Department of Electronics and Information \\ ${ }^{2}$ Department of Management Engineering \\ Politecnico di Milano \\ \{mariagrazia.fugini,piercarlo.maggiolini\}@polimi.it,k.nanini@ hotmail.it \\ Boselli Roberto $^{3}$, Cesarini Mirko ${ }^{3}$, Mezzanzanica Mario ${ }^{3}$ \\ ${ }^{3}$ Department of Statistics, Università degli Studi di Milano Bicocca, \\ \{mirko.cesarini, mario.mezzanzanica\}@unimib.it
}

\begin{abstract}
The objective of this paper is to present a framework to understand the complex and ambiguous phenomenon of Electronic Government (eGovernment) and the several existing models that allow to understand it. Then, the paper discusses the main difficulties in achieving true eGovernment and a way to overcome them. In fact, the eGovernment label has been often given for granted by simply using ICT, e.g. exploiting interoperability frameworks or automatizing services in the Public Administrations. This gave the impression, or even the illusion, of an authentic quality improvement (in efficiency and effectiveness) in the exercise of government functions by different public entities. Actually, in most cases, what happened was only an enhancement in the provisioning of public services, rather than a true improvement of government activities. The paper discusses this misunderstanding and gives hints to achieve true eGovernment functions.
\end{abstract}

\section{Introduction}

Public Organizations essentially carry out two tasks, often in a mixed way, depending on the single Organization: 1) they provide public services to citizens; 2) they govern the collectivity (defined on a territorial basis), promoting and granting common interests (such as health, education, safety, housing, environment, and so on), according to the ways citizens have agreed upon such tasks (through participation - in various forms - to politics).

The two tasks are related. In particular, the first one acts as a tool for the second one, but still the government task does not reach its goal only by delivering public services. Reducing the government tasks to public services provisioning would mean reducing citizens as consumers of those services.

Nowadays, Information and Communication Technologies (ICTs) have been massively introduced in PAs (Public Administrations). Recently, the use, especially when innovative, of ICT in Public Sectors has been called eGovernment (Electronic Government), giving the idea -or the illusion- of an improvement in

Please use the following format when citing this chapter:

Mariagrazia, F., et al., 2008, in IFIP International Federation for Information Processing, Volume 280; E-Government; ICT Professionalism and Competences; Service Science; Antonino Mazzeo, Roberto Bellini, Gianmario Motta; (Boston: Springer), pp. 11-20. 
quality (in terms of efficiency and effectiveness) in government functions by Public Organizations.

By the way, in most cases up to now, what has happened -and is still happening- is more similar to an empowerment and improvement in the use and the provisioning of public services than a real technological support to government activities (including democratic participation).

Furthermore, it is wise questioning whether we are facing a pure terminological misunderstanding (in that case, it would be sufficient to substitute eGovernment with $e$-Administration), or rather a cultural change (transforming citizens from public services consumers to individuals who choose politicians really promoting the creation of infrastructures, even technological, supporting the community interests overcoming the idea -dated back to Aristotle- that individual wellness derives, first of all, from the "city" wellness).

The thesis we are intended to present, in order to give a contribution in terms of a theoretical and a methodological framework, is that ICTs (especially the one related to organizational innovations in PAs) can truly be a tool for eGovernment, in the full meaning of this term.

The paper is organized as follows. Section 2 classifies PA functions, Information Systems supporting PA activities, and Social Systems. Section 3 illustrates PAs and models of employing ICT. Section 4 discusses on eGovernment as a tool for Government to improve political participation and what in our opinion are the difficulties in achieving true eGovernment.

\section{Classifications of PA Functions, of PA In- formation Systems and of Social Systems}

In order to understand the logics underlying the use of ICT and to identify the prevalent models in ICT adoption and diffusion, administrative functions can be classified as follows:

1. Internal administration, for example: human resources and financial management.

2. Service delivery, for any administered entity (citizens and socio-economic agents), such as water services, street cleaning and garbage removal services, healthcare and education, and so on.

3. Government (of collectivity and of her territory), through tools ranging from urban plans to laws on the job marketplace.

On the basis of such classification, we are presenting a taxonomy of PA Information Systems in the following paragraph.

\subsection{A Classification of PA Information Systems}

The trend in Information System development goes into two directions: Administrative and Statistical Information Systems. 
a) Administrative Information Systems: These systems are devoted to public administration management, which is a well-defined and precise task. The systems are fed by documents, as sub-products of administrative acts, which represent the Information sources. This kind of systems have a well defined role for who uses information and the reasons why such information is used, evidencing the reasons of information creation.

Population registries, land registries, car registries, or company registries are examples of Administrative Information Systems.

b) Statistical Information Systems: Statistical Information Systems have no specific users, but they can rather be classified as generic decision makers. In these systems, information collection is typically based on census, polls, markets and registries analysis, inquiries, and so on.

Administrative and Statistical Information System often are inter-related, since their data sources can be used to feed them in one direction or vice versa. Actually, administrative information retrieval is used for statistical purposes: for example, acts related to building concessions can flow into Statistical Information Systems regarding the overall urban activities of a Municipality.

\subsection{A Classification of Social Systems}

A classification of the social systems affected by PA Information Systems is now given, focusing on the kind of integration and organization present among the social system components.

In our approach, Social Systems can be classified as follows: a) Hyperintegrated Systems, b) Meso-integrated Systems, and c) Hypo-integrated Systems.

\section{a) Hyper-integrated Systems}

These are, for instance, a family, a group, or a clan. They do not need formal and structured Information Systems to exchange information, due to the nature of the links among their members. Political parties (on - but not limited to - a local scale), where client-type relationships exist between administrators and citizens, are social phenomena that can be classified as hyper-integrated systems.

Even the related Information System does not need to be formally structured because both information exchanges and communications are informal (since they occur in a context where the transmission of traditions, moral values and norms, and a strong personalization of inter-individual relationships are the most relevant aspects ). In this kind of systems, traditions represent the memory of the hyper-integrated organization, which becomes accessible only after a long apprenticeship (sometimes, a true initiation). The clan organization is not totally extraneous to PA systems, meant as a political system. In fact, such systems are based on trust, values, and norms through relationship sharing.

\section{b) Meso-integrated Systems}

Such systems are "Organizations" in their full meaning. E.g., the systems called bureaucracies are meso-integrated social systems. An industrial company is typically meso-integrated: each department aims at producing specific parts for the final assembly of the whole product. The whole company aims at achieving both 
revenues and profit, related to unit production and sale. Analogously, a Municipality conforms to a meso-integrated system: each councillorship provides services to the administered population, and favors its social and economic development.

\section{c) Hypo-integrated Systems}

A territorial collectivity (a Municipality or a Region) is Hypo-integrated. Each socio-economic unit (agricultural, industrial, commercial, etc.) produces goods or services, which are not per se oriented to the interest of the whole collectivity, but rather to the unit survival and development. Other samples of Hypointegrated systems are the collectivities such as people, an ethnic group, or a Nation.

\subsection{Comparison between meso- and hypo-integrated systems}

In our approach, Municipalities and Regions (hence -latu sensu- Organizations) can be classified both as meso-integrated systems and (in the sense of territorial collectivities) as hypo-integrated systems. Therefore, it is worth detailing the differences between meso- and hyper-integrated systems (Tab.1).

In meso-integrated systems (which are social artifacts, that is, social systems specifically built for a purpose), the organizational structure ruling the subsystems is well identified, and the autonomy degree of the sub-systems is formally defined. Such systems can be easily represented by organizational workflow charts. The system dynamics is observable: a clearly located memory exists in the organization, and it is constituted by procedures and work methods more or less accessible and controllable. This means that in a meso-integrated system institutional and organizational tools can be exploited to pilot the system from one state to another: e.g., a manager can order an employee to perform a task.

Tab. 1: Features of meso- and hypo-integrated systems

\begin{tabular}{|l|}
\hline MESO-INTREGRATED SYSTEMS \\
\hline 1. Each subsystem is clearly oriented to the common task \\
\hline 2. The structure is defined \\
\hline 3. The degree of autonomy of subsystems is formally defined \\
\hline 4. The system dynamics is sufficiently observable and controllable \\
\hline 5. The knowledge (memory) is localized \\
\hline HYPO-INTEGRATED SYSTEMS \\
\hline 1. Each subsystem per se is not targeted to the interest of the whole system \\
\hline 2. The structure is not evident \\
\hline 3. Subsystems have a high degree of autonomy \\
\hline 4. The system dynamics is scarcely observable and controllable \\
\hline 5. The knowledge (memory) is fragmented \\
\hline
\end{tabular}

Instead, hypo-integrated systems create observation problems, since memory is very fragmented: in fact, there are several operators inside who have a high degree of autonomy both in operative and decisional situations. The structure is clear in a hypo-integrated system (although being fluid, dynamic a d very fuzzy) 
but control problems occur. Municipality or Region administrators are not owners of their citizens: they cannot order to a farmer what should be planted or to a company what should be produced or purchased.

During the development of a Public Organization Information System, the Organization is often regarded as a bureaucratic structure, isolated from the territorial context, and operating to achieve only institutional purposes, following welldefined procedures on the basis of laws and norms. In other words, the trend is to limit the Public Organization as a meso-integrated system, while, in a more extended vision, the Municipality and the Region (to resume the above mentioned examples) are a territorial collectivity, and hence, hypo-integrated systems The bureaucratic structure is only a subset of a wider system, where the elective political entities, the administered community, and the whole territory of competence have to be considered according to a holistic view.

\section{PA Organizations and Models Employing ICT}

Basing upon the above proposed way of intending Public Organizations, we identify now four typologies of PA and the related models of Information Systems, according to the information exchange needs and use.

\subsection{Bureaucratic Model}

The Bureaucratic Model conceives a Public Organization as an entity whose task is to emit rules and to control their application: the PAs are in charge of legitimating public-interest matters. A strong separation between politicians and managers undergoes this model. In the bureaucratic model, the Administration is structured around the principle of the conformity of acts, that is, what is relevant for an action undergoes a predefined juridical function. Consequently, all the data generated by PA, are constituted by formal acts registering events (both internal and external), as referencing juridical acts.

Hence, ICT applications mainly take account of registry activities, taxation, certifications, and official acts management (deliberations, regulations, licenses, etc.).

\subsection{Social Model}

The social model regards the Administration as an organization, providing (directly or indirectly) services to the administered citizens. ICTs are used to provide services in a more effective way and the great part of interventions focuses on service automation. The implementation of new information services based on ICT adheres to this view: Public Organizations create special services to inform the community about service availability, about economic, cultural, or sport initiatives taking place in the territory of competence. Up to now, this model of PA and the related use of ICT, is what people call eGovernment. 


\subsection{Using ICT to Support the Social Model: e-Administration}

As discussed previously, eGovernment has often been associated to: "PA supported by ICT". Initially, such support has been exploited to improve backoffice activities: ICT infrastructure have been built meting the specific requirements of the administrative offices (supporting mainly the bureaucratic view, according to our scheme). ICT has played the role of bureaucratic activities supporter for a long time, before it began to overcome the boundaries and became a powerful means to foster interaction with citizens and enterprises on the territory. For several PAs, Internet has immediately resulted in an improvement in terms of availability - web sites are open 24/7 - and of information retrieval - web sites easily retrieve information with a good degree of interaction from home/office. The further step has been to enable on-line form filling: in fact, previously, the forms were downloadable via network but they had to be filled in manually. What became clear soon was that the global rethinking of the procedures, in order to better exploit the Internet and its related technologies.

Such an evolution is nowadays a reality in Europe, but still its development speed varies from Country to Country. Relevant differences can be observerd not only among different Countries, but also -and this is interesting- among population subsets. E.g., services specifically targeted to the enterprises are more developed than those offered to the private citizens.

From various surveys, the emerging idea is that eGovernment, is, till now, essentially limited to the stage of $e$-Administration.

In recent years, ICT has been contributing to make services more and more simple and integrated into a network perspective. Anyway, there are already many problems to solve, due to organizational barriers (opposition to change, obsolete norms) and to technical barriers (e.g., interoperability matters due to obsolete technologies, security and safety, multi-channel devices, and so on).

The great expectation in a significant cost reduction has been the primary goal, leading the development of eGovernment. Actually, such an expectation has turned out to be illusory. The reason is that differently from private organizations (that can select their customers) PA can not refuse to interact with "costly customers", especially since these are users who mostly have to relay on public services (e.g., elderly, handicapped, sick or poor people). Actually, e-Services are added on top of existing services, rather than refactorying them. It is important to understand that eGovernment services can't be regarded as separate from the existing channels of off-line provisioning, i.e., traditional channels based on personal contacts, which often need to be maintained or empowered to grant or improve the quality of service.

\section{4. "Inclusive" eGovernment}

EGovernment (even when limited to e-Administration) should be targeted to provide public services accessible and relevant for each citizen or enterprise (Liikanen, 2003). This means that eGovernment should provide not only efficiency (typical to the enterprises), but also equity, i.e., equal rights and participa- 
tion opportunities for all, and should actuate practically what Liikanen calls inclusion.

Equity is the most important topic for social justice but inclusion is relevant from an economic viewpoint, too: exclusion represents a cost in terms of underutilization of human capital. EGovernment will have its maximum completion when all citizens will be enabled to use technological devices, even though they have low competences, or live in remote regions, or have low incomes, or, in addition, have specific psychological or physical needs.

We have already underlined that Government differs from an enterprise in that it cannot choose its customers, but, instead, it has to serve anybody's needs. If enterprises can focus on efficiency, PA must pursuit both efficiency and equity. From the technological point of view, the devices have to be accurately chosen in order to reach all the population in an equity perspective. For this reason, promoting on-line services only by means of PC would mean excluding a great part of people who are "digitally divided". The number of accesses to Internet via a PC is growing every day; nevertheless, the same on-line services delivered though the Internet could be also delivered by means of, say, interactive TV technology, as TV surely reaches almost all the families. Moreover, other digital devices able to connect to the Internet are rapidly spreading, (e.g., mobile phones, Pocket Digital Assistants and so on), especially among young people.

In summary, a multi-channel approach to information provisioning is needed. However, managing efficiently public service delivery through a multichannel platform is still a hard challenge and calls for a lot of effort, both in terms of money, technologies and human resources. Furthermore, the risk to aggravate the already existing and heavy "Digital Divide" is behind the corner.

\subsection{Political Model}

According to the Political Model, PA are organizations of political governance, that is, the center of socio-economical and territorial planning. The specific nature of the PA as a public entity for political governance emerges straightly. We are now focusing on Municipalities, Provinces or Regions in terms of Organizations, to rather privilege them as Collectivities and Territorial Areas.

PA are well organized and defined entities with juridical orientations and regulations; they have workforce, organizational structures, customers and users. But, beside this, they represent a small part of complex social and territorial systems where people and socio-economic units are integral elements of the administered collectivity. ICT, in this framework, is helpful for:

- governing and controlling political and socio-economic phenomena, creating a qualified information-based network supporting the government activity and planning (in this view, sometimes the term eGovernance is appropriate);

- favoring the relationships between the "Government" (and its institutions) and citizens (single and in associations), allowing their participation and control in the government activities. In this case, it is more appropriate to talk about eDemocracy). 


\subsection{Clan Model}

Finally, the view of the Administration as a "clan" coexists with the other visions, but the "clan" dimension is very important when a relationship (based upon trust) links electors and elected, in the sense of representatives and represented.

Often, the word "clan" assumes a negative connotation. We go over this limited perspective since we simply intend to put into evidence a specific mode of exchanging information in a social system, as the clan organization is.

"Party-cracy" (the occupation of PA by parties) and "lobbing", together with "favoritism groups", represent the degenerated aspects of such an organizational model. However, every time we face a democratic relationship based on trust, involving citizens and representatives, we are in presence of clan logic.

Such a form of clan-based operation is present in most social systems. Anyway, where such organizational form is privileged, it impacts also on the way Information Systems are interpreted and created. Information exchange and personal relationships are going to be informal, as they involve elective organizations. The information exchange is also informal between these entities and the bureaucratic structure, between public administrators and citizens (electors), organized in parties, associations, pressing groups, etc.

If this clan model is ignored, the risk is to disregard a notable (and important) part of the information flow, which is relevant also for the government of the collectivity. In this context, the fundamental role of Civic Networks should be analyzed deeply.

\section{4. eGovernment as a Tool for Government and Political Participation}

Going back to Liikanen's work, eGovernment, first should allow citizens to know how their central, regional and local Administrations operate. Moreover, it should enable people to participate in the decisional processes from the beginning, allowing them also to monitor the expenses of public money.

EGovernment, in this sense, could be a tool to realize Open Government: "eGovernment should help democracy to function better". This means to increase population's involvement and participation in social and political initiatives. Every step of the decisional process should be clear. Open Government, hence, means also increased transparency and responsibility, since they represent a necessity to fight corruption and fraud.

\subsection{Why Is It So Difficult to Achieve True eGovernmet?}

Taking into account the models of PA and their related needs for adequate Information Systems, what is going to be considered now is the

This section is focusing on the reason why ICT is so rarely used to support government activities, taking into account the models of PA previously introduced 
and their related Information System requirements. Some objective difficulties can be identified, besides the lack of political wills on these themes.

Information belongs to the whole in a scattered way, since

The main difficulty in the realization of hypo-integrated Information Systems -and real eGovernment- (e.g. territorial and socio-economic Information Systems) stands in that information describing the several elements of a community (socio-economic and institutional actors) is minimally owned by Public Organizations, since it is disseminated and distributed on the territory: consequently, knowledge is fragmented and is hold by single social units. Under which conditions is it then possible that single social units share their knowledge within the PA context? In our opinion, this is possible only if information suppliers are, directly or indirectly, involved in the information flow either as users or as simple beneficiaries of its exchange. In other words, single social units (families, enterprises, associations, etc.) would rather exchange their personal knowledge only if aware of the advantages they could gain back. Furthermore, knowledge sharing will be more easily set up if collaboration occurs within the exchange process: an information agreement is needed in order to set up and maintain the system (Ciborra et al. 1987). A further reason in adopting a contractual approach to Information Systems relies on the observation of social systems: political ones can be described as negotiated exchange networks. Then, the same Information Systems become a support to negotiation and exchange regulation processes.

Governance and its supporting decisional and Information Systems can be interpreted similarly. According to this approach, public programs and planning are not conceived only as tools of corrective intervention of spontaneous initiatives on the territory, but rather as negotiation and intermediation tools among the different elements playing in the hypo-integrated territorial systems (political parties, trade-unions, economic groups, other PA, etc.). Defining socio-economic targets is not an unilateral act of PAs, but rather the result of a negotiation process carried out by numerous institutional actors, having political, social, and economic nature. Moreover, the negotiation process (both explicit or implicit) does not take into account only the process goals, but also of the indicators to be adopted to outline needs and requirements, or to define standards. The target of the negotiations are the same data that move and feed the government activities as well. Otherwise, it would be hard to understand, for example, the great efforts (often successful, unfortunately), operated by groups of constituted interests and by the same Governments to condition mass media.

Only after understanding the need for the redefinition of government activity, we could achieve a real eGovernment and then move from actual $e$ Administration to eGovernance and e-Democracy (Lenihan, 2002). Table 2 helps to articulate and understand what is included in the different acceptations of eGovernment. 
Tab. 2 Correspondence between models of PA and types of eGovernment

\begin{tabular}{|l|l|}
\hline Public Administration Models & eGovernment Types \\
\hline Bureaucratic Model & eAdministration \\
\hline Social Model & EAdministration (ePublic Services) \\
\hline Political Model & $\begin{array}{l}\text { Actual eGovernment (eGovernance; eDe- } \\
\text { mocracy) }\end{array}$ \\
\hline "Clan" Model & eDemocracy; Civic Networks \\
\hline
\end{tabular}

\section{Acknowledgments.}

This paper has been partially supported by the Italian TEKNE Project.

\section{References}

- Ciborra, C., and Gasbarri, G., and Maggiolini P. "System design for local authorities: Participation based on 'Information Contracts", in System design for human development and productivity: Participation and beyond, P. Docherty, and Fuchs-Kittowski K., and Kolm P., and Mathiassen L. (eds), NorthHolland, Amsterdam, 1987

- Lenihan, D.G. "Realigning Governance: From EGovernment to EDemocracy", Centre for Collaborative Government, Ottawa, April 2002

- Liikanen, E. "EGovernment and the European Union", UPGrade, Vol. IV, No. 2, April 2003 